BMJ Open

Diabetes

Research

\& Care

\title{
Effect of CETP inhibition with evacetrapib in patients with diabetes mellitus enrolled in the ACCELERATE trial
}

\author{
Venu Menon (D) , ${ }^{1}$ Anirudh Kumar (D) , ${ }^{1}$ Divyang R Patel, ${ }^{1}$ Julie St John, ${ }^{1}$ \\ Jeffrey Riesmeyer, ${ }^{2}$ Govinda Weerakkody, ${ }^{2}$ Giacomo Ruotolo, ${ }^{2}$ Kathy E Wolski, ${ }^{1}$ \\ Ellen McErlean, ${ }^{1}$ Paul C Cremer, ${ }^{1}$ Stephen J Nicholls, ${ }^{3}$ A Michael Lincoff, ${ }^{1}$ \\ Steven E Nissen ${ }^{1}$
}

To cite: Menon V, Kumar A, Patel DR, et al. Effect of CETP inhibition with evacetrapib in patients with diabetes mellitus enrolled in the ACCELERATE trial. BMJ Open Diab Res Care 2020;8:e000943. doi:10.1136/ bmjdrc-2019-000943

\section{- Additional material is} published online only. To view please visit the journal online (http://dx.doi.org/10.1136/ bmjdrc-2019-000943).

Received 1 October 2019 Revised 23 January 2020 Accepted 31 January 2020
Check for updates

C) Author(s) (or their employer(s)) 2020. Re-use permitted under CC BY-NC. No commercial re-use. See rights and permissions. Published by BMJ.

${ }^{1}$ Heart and Vascular Institute, Cleveland Clinic Foundation, Cleveland, Ohio, USA ${ }^{2}$ Eli Lilly and Company, Indianapolis, Indiana, USA ${ }^{3}$ Monash Cardiovascular Research Centre, Monash University, Melbourne, Victoria, Australia

Correspondence to Dr Venu Menon; menonv@ccf.org

\section{ABSTRACT}

Background High-density lipoprotein (HDL) levels are inversely associated with cardiovascular risk. Cholesteryl ester transfer protein inhibition with evacetrapib results in a marked increase in HDL and reduction in low-density lipoprotein (LDL) levels. We evaluated the impact of treatment with evacetrapib versus placebo in the subset of 8236 patients with diabetes mellitus (DM) enrolled in the Assessment of Clinical Effects of Cholesteryl Ester Transfer Protein Inhibition with Evacetrapib in Patients at a High Risk for Vascular Outcomes trial.

Methods and results Time to first occurrence of any component of the primary composite endpoint of cardiovascular death, myocardial infarction, stroke, revascularization, and hospitalization for unstable angina was compared among patients with DM randomized to treatment with evacetrapib $(n=4127)$ or placebo $(n=4109)$ over a median of 26 months of follow-up. The mean baseline LDL at initiation was $80 \mathrm{mg} / \mathrm{dL}$ with a mean baseline $\mathrm{HDL}$ of $44 \mathrm{mg} / \mathrm{dL}$. In patients with $\mathrm{DM}$, evacetrapib resulted in a $131 \%$ mean increase in HDL levels and a $32 \%$ mean decrease in LDL at 3 months that was sustained during the course of the trial. At 6 months, hemoglobin $\mathrm{A} 1 \mathrm{c}(\mathrm{HbA1c})$ levels were lower with evacetrapib than placebo $(7.08 \%$ vs $7.15 \%, p=0.023)$. Composite event rates were higher in patients with DM than without DM (Kaplan-Meier estimates: $15.2 \%$ vs $10.6 \%$, HR 1.46, 95\% Cl 1.30 to $1.64, p<0.001)$. In the DM group, event rates for the composite endpoint (14.5\% evacetrapib vs $16 \%$ placebo, HR $0.95,95 \% \mathrm{Cl} 0.85$ to $1.07, p=0.38$ ) and individual components of the composite were similar for both evacetrapib and placebo groups. No significant treatment interaction between treatment assignment and diabetes status was noted.

Conclusion Despite a favorable increase in HDL, and decreases in LDL and $\mathrm{HbA1c}$ levels in patients with DM, we observed no benefits of treatment with evacetrapib on prespecified clinical outcomes in this high-risk population.

\section{INTRODUCTION}

Urbanization, rising living standards and increased rates of obesity have all contributed to a marked increase in the population

\section{Significance of this study}

What is already known about this subject?

- Despite contemporary optimal medical therapy, patients with diabetes remain at elevated risk for cardiovascular events compared with their counterparts without diabetes. As such, they are important targets for novel agents which may mitigate cardiovascular risk.

What are the new findings?

- Among patients with diabetes, use of evacetrapib resulted in significant and sustained improvements in low-density lipoprotein, high-density lipoprotein (HDL), and hemoglobin A1c.

- Despite this, there were no benefits of treatment with evacetrapib on prespecified clinical outcomes in this high-risk population.

How might these results change the focus of research or clinical practice?

- Why do patients with diabetes remain at elevated risk for cardiovascular events despite optimal, guideline-recommended medical therapy?

- Why did cholesteryl ester transfer protein inhibition fail to reduce cardiovascular events among patients with diabetes?

- Is there another therapeutic mechanism by which increasing HDL can translate into improved cardiovascular outcomes?

affected by type 2 diabetes mellitus (DM). Worldwide, over 400 million adults are currently affected with DM and this number is expected to increase to 642 million by 2040 . A new diagnosis of $\mathrm{DM}$ in the fifth decade is associated with 5-6years of reduction in longevity in both men and women, mainly 
as a consequence of complications from cardiovascular disease. $^{2}$

Epidemiological studies have suggested a strong inverse relationship between high-density lipoprotein (HDL) cholesterol levels and observed cardiovascular risk. ${ }^{3-6} \mathrm{~A}$ cardioprotective benefit of elevated HDL levels has also been suggested in some, but not all, genetic studies. ${ }^{7-10}$ Diabetic dyslipidemia is characterized by a high prevalence of low HDL levels, elevated triglycerides, increased lipoprotein(a), and dense low-density lipoprotein (LDL) levels. ${ }^{11}$ While patients with DM benefit greatly from intense statin therapy, these agents have a minor impact on observed HDL levels. ${ }^{12}$

Evacetrapib, a potent cholesteryl ester transfer protein (CETP) inhibitor, when added to a high-dose statin, has been shown to increase HDL levels by approximately $130 \%$, lower LDL levels by $30 \%-35 \%$, and decrease levels of lipoprotein(a). ${ }^{13}$ These biochemical actions mediated via inhibiting the transfer of cholesterol ester from HDL to apolipoprotein B (ApoB) containing lipoproteins were expected to translate into favorable clinical outcomes in high-risk cardiovascular patients. However, no benefits were noted in the Assessment of Clinical Effects of Cholesteryl Ester Transfer Protein Inhibition with Evacetrapib in Patients at a High Risk for Vascular Outcomes (ACCELERATE) trial. ${ }^{14}$ In this manuscript, we detail the lipid modification and clinical impact of treatment with evacetrapib compared with placebo in the large subset of trial participants with DM enrolled in this clinical trial.

\section{METHODS}

Study design

The design, conduct and outcomes of the overall results of the ACCELERATE trial have been previously published. ${ }^{1415}$ Briefly, this international, multicenter trial prospectively randomized 12092 subjects with a prior acute coronary syndrome, stroke, symptomatic peripheral vascular disease, or diabetes with established coronary artery disease to treatment with evacetrapib $130 \mathrm{mg}$ daily or placebo. Nearly all study participants with the exception of those intolerant to statin $(96.5 \%)$ were treated with these agents at trial onset. The primary efficacy endpoint was the first occurrence of any component of the composite of cardiovascular death, myocardial infarction, stroke, revascularization, and hospitalization for unstable angina. Due to clinical futility for the primary composite endpoint, the trial was terminated prematurely. The median exposure to study drug/ placebo at study termination was 26 months with an IQR of 23-29 months. Follow-up of participants for clinical events was near complete with an end of study visit completed in $98.8 \%$ of trial participants. Data from patients who withdrew consent or were lost to follow-up were censored at the time of withdrawal or at the time that the patient was last known to be free from having a composite endpoint event. Clinical events were identified and prospectively adjudicated by an independent clinical endpoints committee blinded to treatment assignment using prespecified standardized definitions.

\section{Statistical methods}

All randomized patients were included in this prespecified analysis on an intention-to-treat basis. Patients with DM were defined as those receiving treatment with an oral or parenteral antiglycemic agent and/or insulin or being managed by diet alone as a result of a pre-existing diagnosis of DM. A new diagnosis of DM was based on fasting plasma glucose measurements $\geq 126 \mathrm{mg}$ / dL, 2-hour plasma glucose $\geq 200 \mathrm{mg} / \mathrm{dL}$ during an oral glucose tolerance test, or hemoglobin A1c (HbA1c) level $\geq 6.5 \%$. Baseline clinical characteristics in patients with and without DM were compared. Treatment groups were compared on major side effects in patients with DM as well as on the incidence of those with new-onset diabetes. Continuous variables were compared between groups using Student's t-test for normally distributed variables or Wilcoxon rank-sum test for non-normally distributed variables. Mean \pm SD or median with IQR are reported respectively. Categorical variables were compared between groups using Pearson $\chi^{2}$ or Fisher's exact test. Frequency and percent are reported.

The primary composite endpoint was defined as the time to first occurrence of cardiovascular death, myocardial infarction, stroke, hospitalization for unstable angina, or coronary revascularization. Additionally, a triple composite endpoint of time to first occurrence of cardiovascular death, myocardial infarction, or stroke was also included. Survival analysis was performed to assess the incidence of primary composite and individual endpoints within and across DM and treatment group combinations. Kaplan-Meier (KM) estimates of event rates are reported and compared between groups using a log-rank test. Cox proportional hazards modeling was used to compare evacetrapib to placebo within DM and non-DM patients as well as test the treatment by DM interaction for each endpoint. HRs with $95 \%$ CIs are reported. $\mathrm{KM}$ curves illustrate the incidence of the primary and triple composite endpoints over time. The clinical endpoints were truncated at 915 days (30 months) due to study termination. Changes in HDL, LDL, and HbAlc were assessed over time within treatment and DM groups using mixed modeling with repeated measures while adjusting for respective baseline measures. Least squares (LS) means with SE bars are plotted over time. Tests were two tailed with a 0.05 significance level. Analysis was performed using SAS V.9.4 (SAS Institute). Figures were created using SigmaPlot V.11.0 (Systat Software, San Jose, CA).

\section{RESULTS}

\section{Baseline characteristics}

The ACCELERATE trial enrolled 12092 patients between October 2012 and December 2013 and 8236 (68\%) were known to have DM at study initiation (figure 1). 


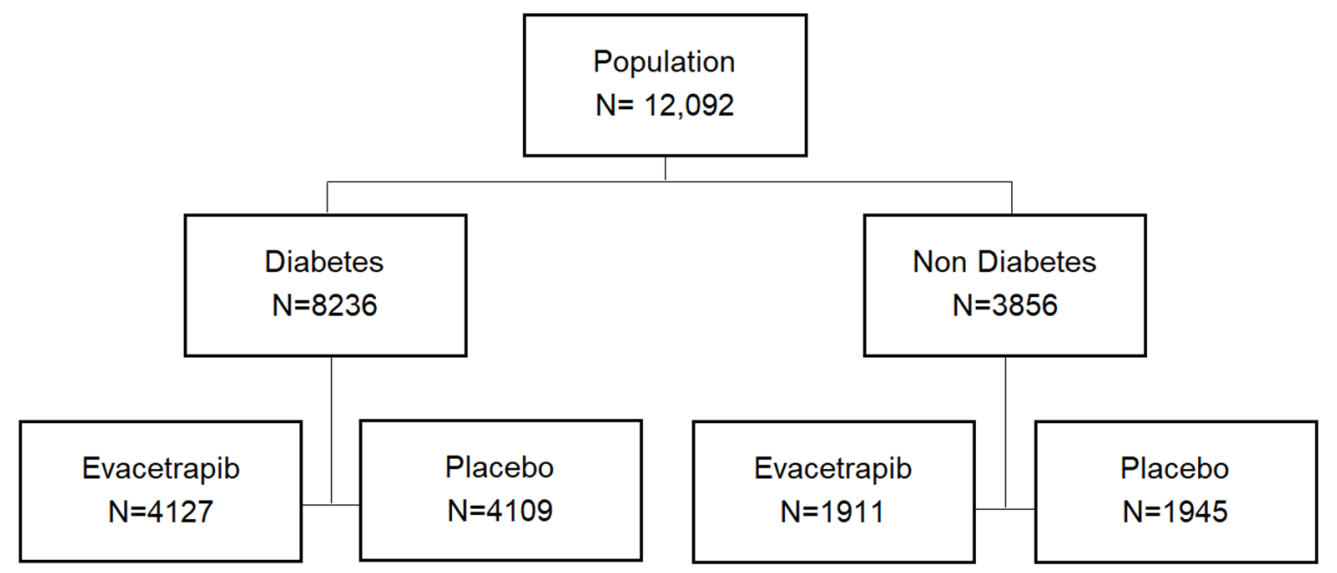

Figure 1 Flow diagram showing patients with diabetes mellitus enrolled in the Assessment of Clinical Effects of Cholesteryl Ester Transfer Protein Inhibition with Evacetrapib in Patients at a High Risk for Vascular Outcomes (ACCELERATE) trial and their assignment to treatment evacetrapib or placebo.

Among trial participants with DM, 4127 were assigned to treatment with evacetrapib and 4109 were assigned to placebo. Baseline characteristics of trial participants with and without DM are presented in table 1.

Among those with and without DM, there were no significant differences in baseline characteristics among those assigned to treatment with evacetrapib or placebo (online supplementary material). The baseline mean LDL cholesterol levels at study initiation were significantly lower in patients with DM $(80 \pm 27$ vs $84 \pm 29 \mathrm{mg}$ / $\mathrm{dL}, \mathrm{p}<0.001)$ as were the baseline mean HDL cholesterol levels $(44 \pm 11$ vs $48 \pm 12 \mathrm{mg} / \mathrm{dL}, \mathrm{p}<0.001)$ with significantly greater triglyceride levels $(154 \pm 80$ vs $133 \pm 75 \mathrm{mg} / \mathrm{dL}$, $\mathrm{p}<0.001)$. At study initiation, $98 \%$ of patients with $\mathrm{DM}$ were on a statin with $46 \%$ receiving intense-dose therapy; this finding was similar to patients without DM enrolled in the trial. Rates of aspirin utilization were significantly higher in patients with DM.

\section{Impact of treatment with evacetrapib on lipids}

At 3 months, the mean HDL cholesterol in patients with DM treated with evacetrapib had increased from $44 \pm 11$ to $101 \pm 30 \mathrm{mg} / \mathrm{dL}$, a mean increase of $131 \% \pm 56 \%$. This was significantly higher than the $1 \% \pm 17 \%$ change in HDL noted in placebo-treated patients with DM during the same time period $(\mathrm{p}<0.001)$. Treatment with evacetrapib also decreased LDL cholesterol levels in patients with DM from a baseline of $80 \pm 27 \mathrm{mg} / \mathrm{dL}$ to $53 \pm 25 \mathrm{mg} / \mathrm{dL}$, a mean decrease of $32 \% \pm 28 \%$, which was significantly lower than the $6 \% \pm 29 \%$ increase in LDL levels noted in placebo-treated patients with DM during this time period $(p<0.001)$. Changes in lipid levels stratified by the presence or absence of DM and exposure to evacetrapib/ placebo over the course of the trial are shown in figure 2. Consistent with results from the phase 2 program, exposure to evacetrapib resulted in a large, early and sustained increase in measured HDL levels compared with placebo in patients with and without DM, a difference that was maintained during the course of the clinical study (figure 2A). Treatment with evacetrapib also resulted in a significant early and sustained decrease in LDL cholesterol levels compared with placebo in both patients with and without DM (figure 2B).

\section{Clinical outcomes}

The primary composite event rate for patients with DM during the course of the trial regardless of treatment assignment was significantly greater than that observed in their counterparts without DM (KM estimates: $15.2 \%$ vs $10.6 \%$, HR $1.46,95 \%$ CI 1.30 to $1.64, \mathrm{p}<0.001)$. The adjusted HR comparing those with DM to those without DM on the composite endpoint was 1.29 (95\% CI 1.14 to 1.46 ) with $\mathrm{p}<0.001$ after adjusting for age, gender, smoking status, renal impairment, body mass index, and presence of hypertension. Figure 3A illustrates the KM curves for the primary composite endpoint observed in patients with and without DM based on treatment assigned. Outcomes for patients with DM assigned to treatment with evacetrapib or placebo were similar ( $14.5 \%$ vs $16.0 \%$, HR $0.95,95 \%$ CI 0.85 to $1.07, \mathrm{p}=0.38$ ). Similarly, composite event rates in patients without DM were numerically lower but similar regardless of assignment to evacetrapib or placebo ( $11.5 \%$ vs $9.7 \%$, HR 1.17 , $95 \%$ CI 0.96 to $1.44, \mathrm{p}=0.12$ ). As shown in figure $3 \mathrm{~B}$, event rates for the triple composite endpoint of cardiovascular death, myocardial infarction, and stroke were also similar for patients with DM exposed to evacetrapib or placebo ( $8.2 \%$ vs $9.4 \%$, HR $0.91,95 \%$ CI 0.79 to 1.06 , $\mathrm{p}=0.25)$ as well as in patients without DM (6.3\% vs $5.5 \%$, HR $1.09,95 \%$ CI 0.83 to $1.44, p=0.54)$. KM estimates for individual components of the composite endpoint in the group with and without DM by treatment assigned are presented in table 2 and are similar with no evidence of a statistically significant interaction between DM and treatment assigned.

A sensitivity multivariable model for the exposure to evacetrapib on the primary composite endpoint adjusting for age, male gender, history of coronary artery disease, peripheral vascular disease, cerebral vascular disease, hypertension, smoking, heart failure, renal impairment, 
Table 1 Characteristics of patients with and without diabetes mellitus at baseline

\begin{tabular}{|c|c|c|c|}
\hline & $\begin{array}{l}\text { Diabetes } \\
(n=8236)\end{array}$ & $\begin{array}{l}\text { Non-diabetes } \\
(\mathrm{n}=3856)\end{array}$ & $P$ value \\
\hline Mean age (years) $\pm S D$ & $65.5 \pm 8.7$ & $62.2 \pm 10.4$ & $<0.001$ \\
\hline Male sex (\%) & 76 & 78 & 0.008 \\
\hline Race (\%) & & & $<0.001$ \\
\hline White & 78 & 91 & \\
\hline Black & 3.0 & 1.4 & \\
\hline Asian & 13.4 & 5.0 & \\
\hline Other & 5.3 & 2.7 & \\
\hline $\begin{array}{l}\text { Mean body mass } \\
\text { index } \pm S D\end{array}$ & $31.1 \pm 5.9$ & $28.3 \pm 4.7$ & $<0.001$ \\
\hline \multicolumn{4}{|l|}{ Index diagnosis (\%) } \\
\hline $\begin{array}{l}\text { Recent ACS 30-365 } \\
\text { days }\end{array}$ & 16 & 61 & $<0.001$ \\
\hline $\begin{array}{l}\text { Cerebrovascular } \\
\text { disease }\end{array}$ & 21 & 25 & $<0.001$ \\
\hline $\begin{array}{l}\text { Peripheral arterial } \\
\text { disease }\end{array}$ & 17 & 26 & $<0.001$ \\
\hline CAD & 93 & 83 & $<0.001$ \\
\hline \multicolumn{4}{|c|}{ Cardiovascular risk factors (\%) } \\
\hline Hypertension & 92 & 78 & $<0.001$ \\
\hline Current smoker & 14 & 20 & $<0.001$ \\
\hline $\begin{array}{l}\text { Prior myocardial } \\
\text { infarction }\end{array}$ & 60 & 83 & $<0.001$ \\
\hline Prior $\mathrm{PCl}$ & 71 & 74 & 0.001 \\
\hline Prior CABG & 33 & 20 & $<0.001$ \\
\hline Prior heart failure & 15 & 11 & $<0.001$ \\
\hline COPD & 11 & 10 & 0.08 \\
\hline Renal impairment & 11 & 5 & $<0.001$ \\
\hline \multicolumn{4}{|l|}{ Lipids (mg/dL) } \\
\hline Mean LDL cholesterol & $80 \pm 27$ & $84 \pm 29$ & $<0.001$ \\
\hline Mean HDL cholesterol & $44 \pm 11$ & $48 \pm 12$ & $<0.001$ \\
\hline $\begin{array}{l}\text { Median triglyceride } \\
\text { (IQR) }\end{array}$ & $\begin{array}{l}136 \\
(99,187)\end{array}$ & $\begin{array}{l}113 \\
(85,158)\end{array}$ & $<0.001$ \\
\hline $\begin{array}{l}\text { Mean apolipoprotein } \\
\text { A1 }\end{array}$ & $137 \pm 25$ & $142 \pm 26$ & $<0.001$ \\
\hline $\begin{array}{l}\text { Mean apolipoprotein } \\
\text { B }\end{array}$ & $78 \pm 22$ & $78 \pm 23$ & $<0.001$ \\
\hline $\begin{array}{l}\text { Median lipoprotein(a) } \\
\text { (IQR) }\end{array}$ & $\begin{array}{l}27 \\
(10,99)\end{array}$ & $\begin{array}{l}32 \\
(13,125)\end{array}$ & $<0.001$ \\
\hline $\begin{array}{l}\text { Median HS CRP (IQR) } \\
\text { (mg/L) }\end{array}$ & $\begin{array}{l}1.53 \\
(0.75,3.42)\end{array}$ & $\begin{array}{l}1.44 \\
(0.71,3.03)\end{array}$ & 0.003 \\
\hline \multicolumn{4}{|l|}{ Medications (\%) } \\
\hline Any statin & 96 & 97 & 0.011 \\
\hline High-intensity statin & 43 & 55 & $<0.001$ \\
\hline ACEi/ARB & 80 & 72 & $<0.001$ \\
\hline Aspirin & 84 & 81 & 0.002 \\
\hline
\end{tabular}

ACEi, ACE inhibitor; ACS, acute coronary syndrome; ARB, angiotensin-receptor blocker; CABG, coronary artery bypass graft; CAD, coronary artery disease; COPD, chronic obstructive pulmonary disease; HDL, high-density lipoprotein; HS CRP, high-sensitivity Creactive protein; LDL, low-density lipoprotein; $\mathrm{PCl}$, percutaneous coronary intervention. and LDL remained non-significant in both patients with diabetes (HR 0.94, 95\% CI 0.84 to $1.06, \mathrm{p}=0.35$ ) and patients without diabetes (HR 1.14, 95\% CI 0.93 to $1.40, \mathrm{p}=0.20$ ) with no statistically significant interaction between DM and treatment assigned $(p=0.12)$.

\section{Impact on glycemic control}

The baseline HbAlc in patients with DM randomized to evacetrapib and placebo was similar $(7.09 \% \pm 1.37 \%$ vs $7.08 \% \pm 1.38 \%, \mathrm{p}=0.68)$. Figure $4 \mathrm{~A}$ compares the LS means change in $\mathrm{HbAlc}$ levels over time for patients with DM. Exposure to evacetrapib was associated with a small but significant improvement in glycemic profile over the course of the trial $(\mathrm{p}=0.016)$. The rates of new-onset DM were similar with exposure to evacetrapib compared with placebo $(9.2 \%$ vs $10.3 \%$, $\mathrm{p}=0.24)$ (figure $4 \mathrm{~B}$ ).

\section{Adverse events}

The adverse events experienced by patients with DM by treatment assignment during the course of the trial are shown in table 3 .

The incidence of acute pancreatitis was numerically small but statistically significant for patients exposed to evacetrapib compared with placebo. The rate of reduction in estimated glomerular filtration rate during trial duration was significantly lower in the evacetrapib group. No patients met criteria for new-onset hemodialysis during conduct of the trial.

\section{DISCUSSION}

The present study was a prespecified analysis of the ACCELERATE trial that demonstrated a lack of treatment benefit with evacetrapib in patients with DM at high risk for cardiovascular events despite sustained elevation in HDL levels with significant decreases in LDL and an improved glycemic profile. Another notable finding is the markedly elevated risk for cardiovascular events among patients with DM despite state-of-the-art treatment with statin, antiplatelet therapy, blood pressure control and favorable baseline LDL cholesterol levels. The annualized event rates observed in patients with DM in ACCELERATE were significantly higher than their counterparts without DM and are consistent with the rates observed in multiple contemporary cardiovascular outcome trials evaluating newer antiglycemic agents. ${ }^{16-20}$ These elevated event rates occurred despite the background of statin therapy and a baseline LDL of $80 \mathrm{mg} / \mathrm{dL}$ at study initiation that met optimal guideline targets. ${ }^{21} 22$ Given the exponential rise in the population of patients with DM, these findings suggest an increase in the burden of cardiovascular morbidity in the coming decades and emphasize the need to identify novel therapeutic targets that will reduce the atherosclerotic risk in this vulnerable population.

Heightened cardiovascular risk in DM is multifactorial with dyslipidemia playing a major contributory role. ${ }^{1}$ While the efficacy of statin treatment, ezetimibe, and PCSK9 inhibitors in cardiovascular risk reduction in the setting of DM 
A

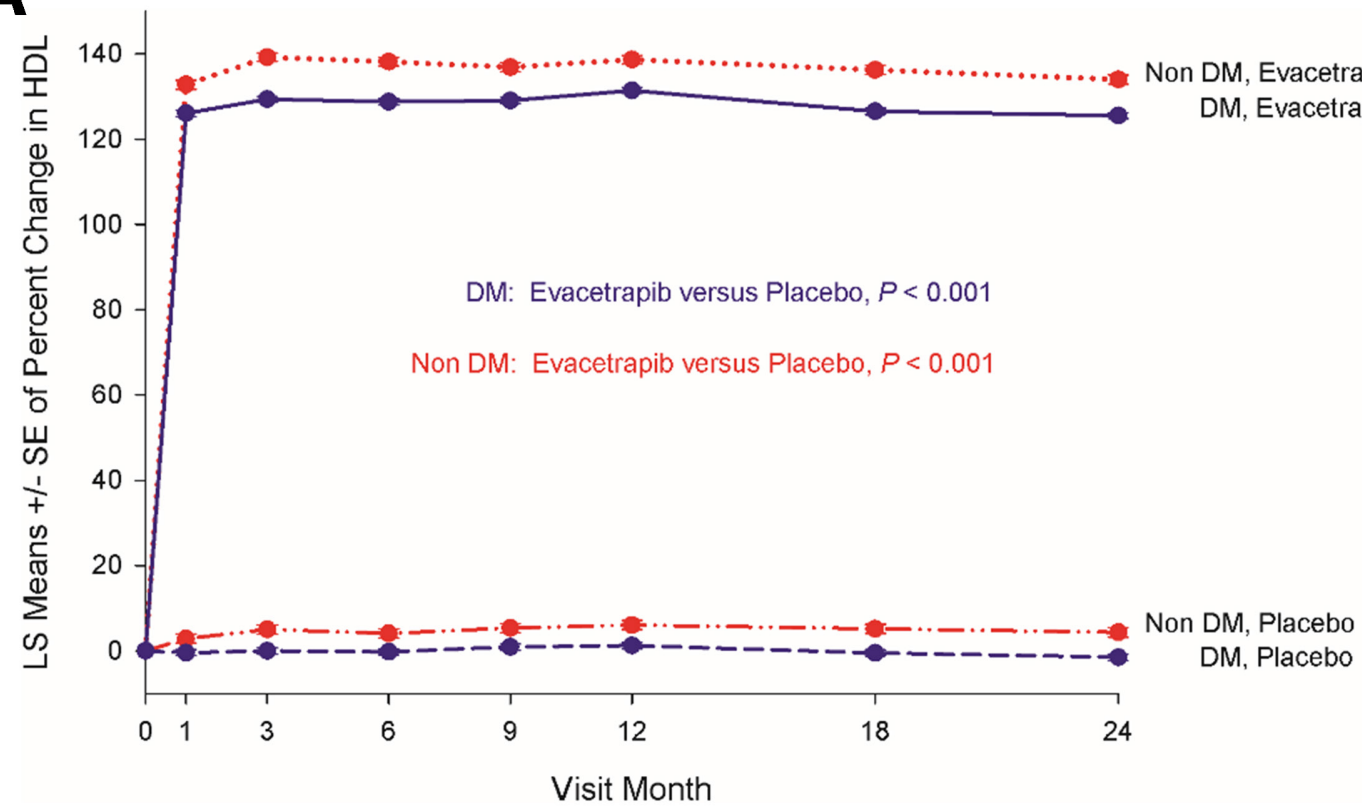

B

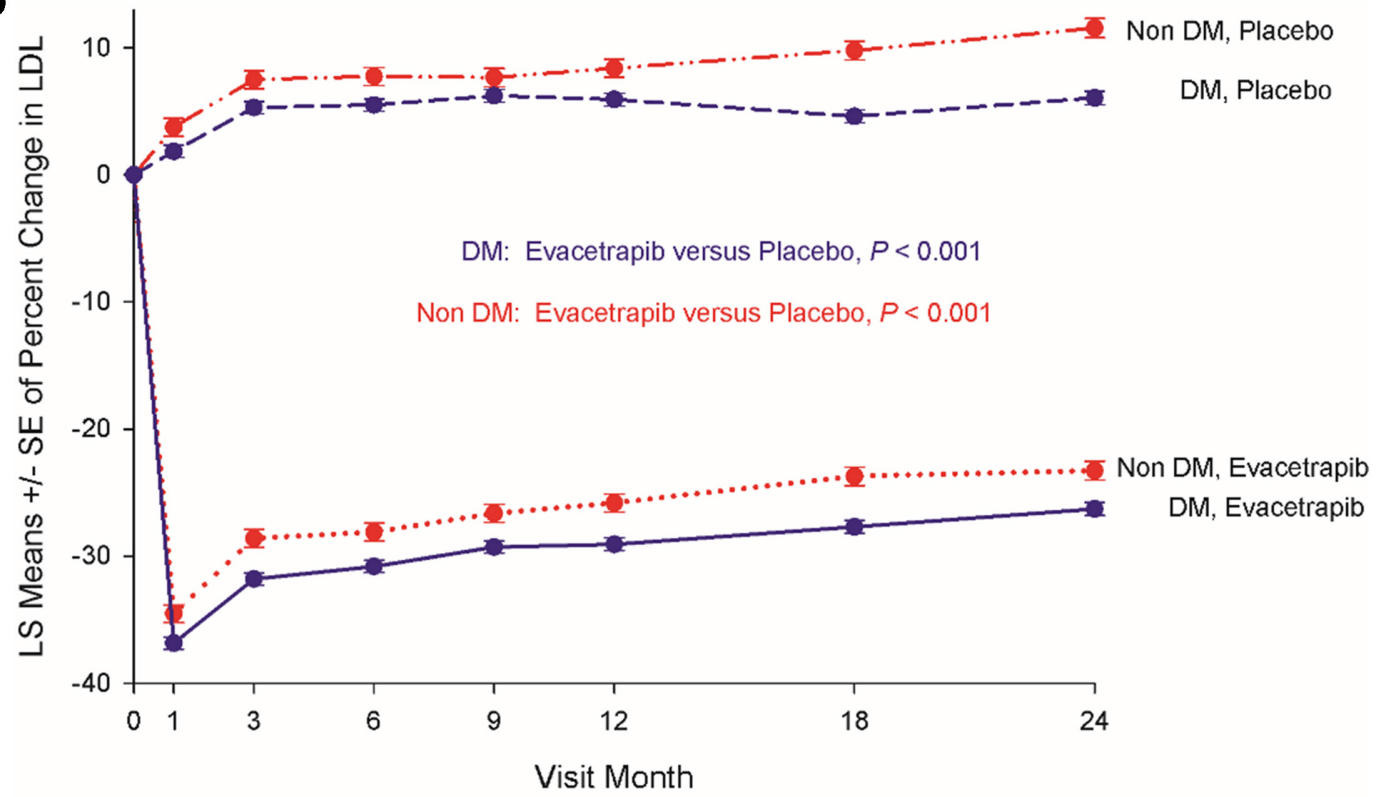

Figure 2 Impact of exposure to evacetrapib on HDL (A) and LDL (B) measurements among patients with and without diabetes mellitus in the Assessment of Clinical Effects of Cholesteryl Ester Transfer Protein Inhibition with Evacetrapib in Patients at a High Risk for Vascular Outcomes (ACCELERATE) trial. DM, diabetes mellitus; HDL, high-density lipoprotein; LDL, low-density lipoprotein; LS, least squares.

is now established, these favorable benefits are mediated via a reduction in LDL cholesterol. ${ }^{112324}$ The high prevalence of low HDL levels in the population with DM and the epidemiological and genetic observation favoring the protective effects of elevated HDL cholesterol levels made this population of special therapeutic interest when potent CETP inhibitors, with the ability to favorably modify HDL levels, were developed and tested. While prior CETP inhibition with torcetrapib was complicated by off-target side effects and observed harm, the lack of benefit observed with dalcetrapib was attributed to its low potency and its being tested exclusively in the acute coronary syndrome setting. ${ }^{25}{ }^{26}$ Evacetrapib is a potent CETP inhibitor with a safe risk profile and in phase 2 trials increased HDL levels by $130 \%$ with evidence of functionality as observed by an increased cholesterol efflux capacity, ${ }^{27}$ a feature that is strongly associated with cardiovascular protection in epidemiological observations. ${ }^{28}{ }^{29}$ As a result, the agent was thought to hold great promise as a novel therapeutic agent especially in the population with DM. Our study findings from the ACCELERATE trial in over 8000 patients with DM confirm that this is not the case. Although exposure to 


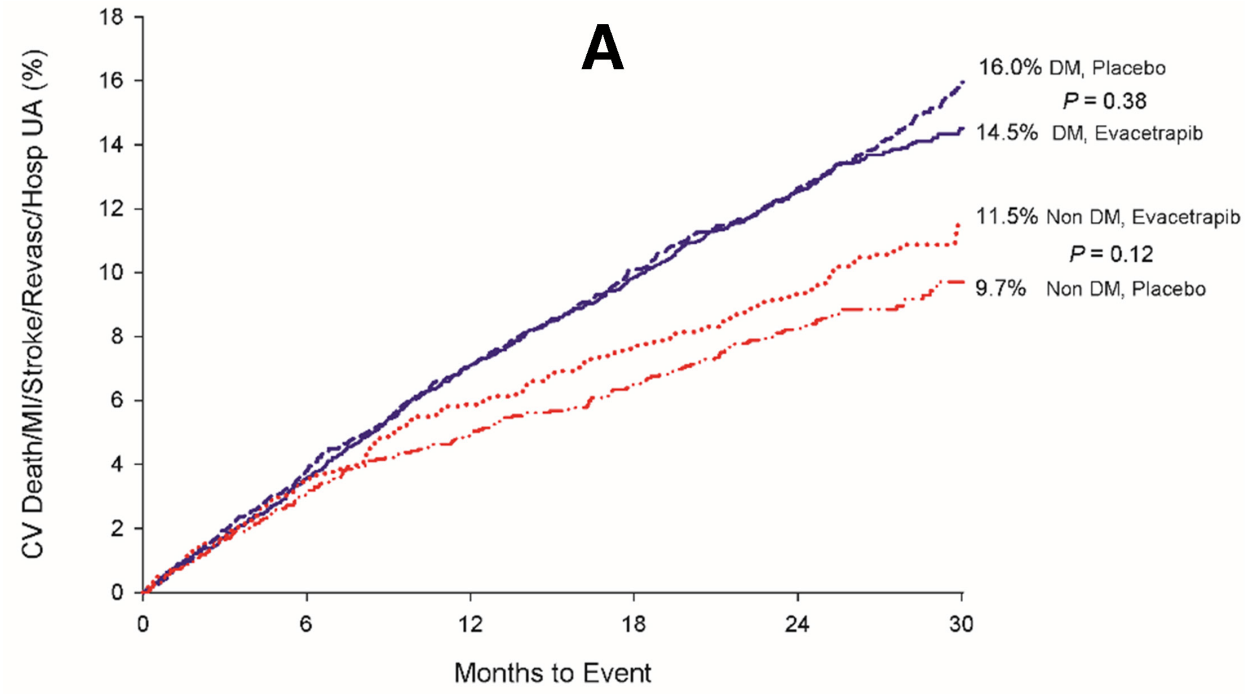

$\begin{array}{lllllll}\text { No. at Risk } & & & & & & \\ \text { DM, P } & 4109 & 3937 & 3789 & 3644 & 3218 & 912 \\ \text { DM, E } & 4127 & 3971 & 3811 & 3678 & 3240 & 927 \\ \text { No DM, E } & 1911 & 1841 & 1788 & 1744 & 1547 & 401 \\ \text { No DM, P } & 1945 & 1882 & 1837 & 1795 & 1586 & 419\end{array}$

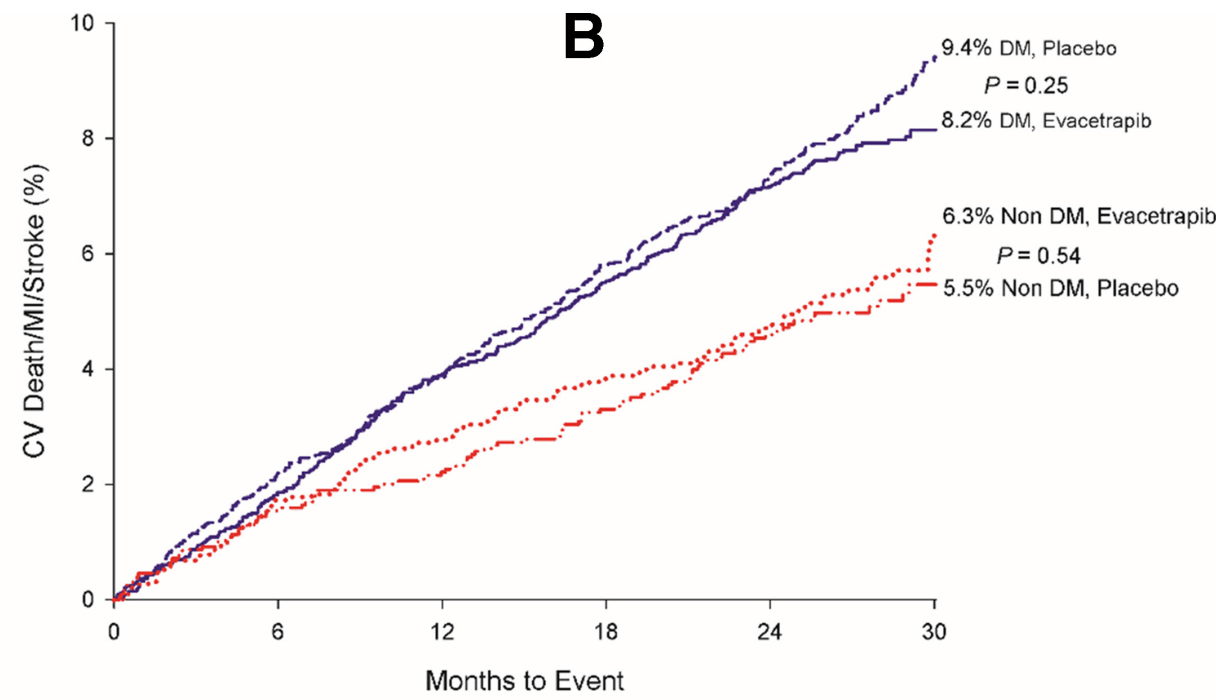

$\begin{array}{lcccccc}\text { No. at Risk } & & & & & \\ \text { DM, P } & 4109 & 4002 & 3919 & 3817 & 3411 & 980 \\ \text { DM, E } & 4127 & 4042 & 3942 & 3853 & 3430 & 990 \\ \text { No DM, E } & 1911 & 1874 & 1847 & 1817 & 1624 & 424 \\ \text { No DM, P } & 1945 & 1912 & 1890 & 1857 & 1647 & 433\end{array}$

Figure 3 Impact of exposure to evacetrapib on the composite (A) and triple composite endpoint (B) outcome among patients with diabetes mellitus randomized to treatment with evacetrapib or placebo. CV, cardiovascular; DM, diabetes mellitus; MI, myocardial infarction; $U A$, unstable angina.

evacetrapib resulted in a prompt and sustained elevation in plasma HDL levels, we observed no favorable impact on clinical outcomes over a median of 26 months of follow-up. This lack of benefit was also present despite a favorable $32 \%$ reduction in LDL levels with treatment with this agent and is in contrast to the Randomized Evaluation of the Effects of Anacetrapib through Lipid Modification (REVEAL) trial which reported a statistically significant but clinically small $9 \%$ relative risk reduction. ${ }^{30}$
Although speculative, the lack of benefit with evacetrapib in patients with and without DM deserves comment. The first explanation is that the prior epidemiological and genetic association between higher HDL levels and reduced cardiovascular risk is an epiphenomenon with no direct causal relationship. As a result, numerical improvement in HDL levels did not translate into a meaningful clinical benefit. Second, the 26 months median time to follow-up may not have been adequate 


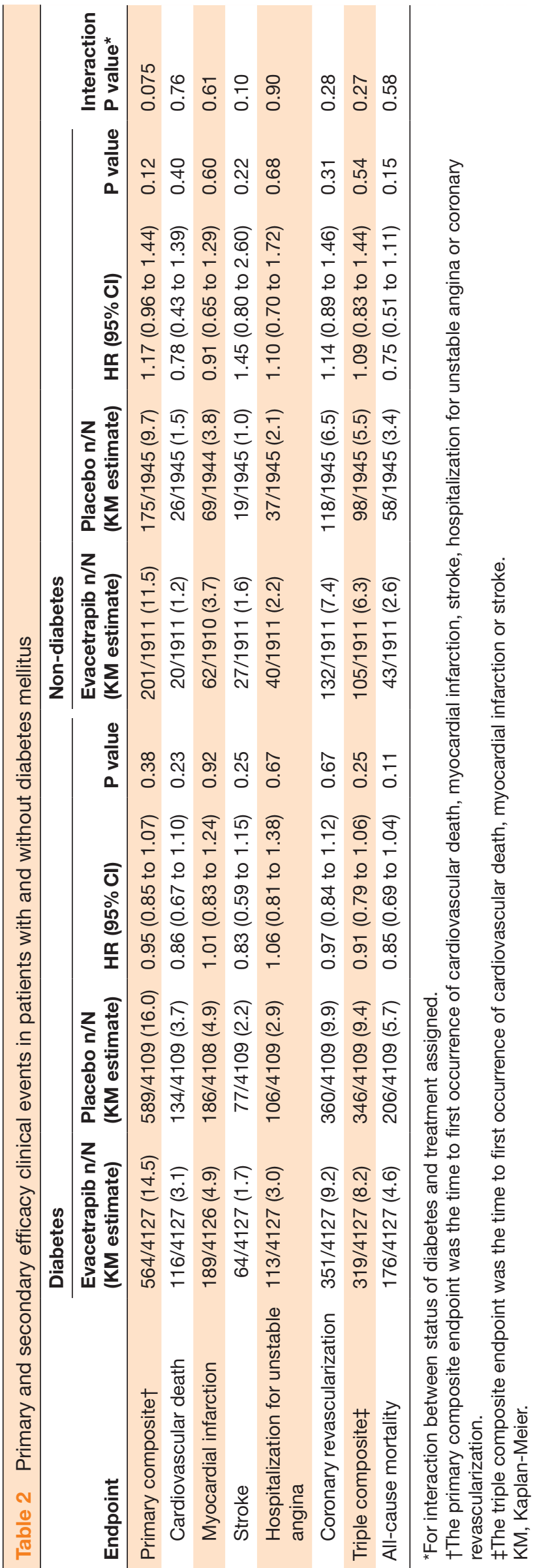

to discern potential clinical benefit given the latency of therapeutic effect observed in prior interventions of favorable LDL lipid modification. While this is possible, it does not appear to be the case as the event curves in ACCELERATE remain superimposed throughout the period of follow-up with no evidence of any decline in atherosclerotic events as was seen with LDL-lowering agents like PCSK9 inhibitors, ezetimibe, and with agents like GLP1 agonists liraglutide and semiglutide within this time period. ${ }^{11202331}$ A clinical benefit with HDL rising was also not observed with anacetrapib during the initial 2 years of follow-up in over 30000 patients. It is possible that an unrecognized adverse or off-target side effect may have accounted for these findings by countering the favorable benefits accrued from lipid modification. We however observed no harmful side effects during close monitoring of patients in the setting of a randomized clinical trial designed for regulatory approval. Harm also appears unlikely given the consistency of event rates in the placebo and treatment groups during the entire course of the trial. We did note a $1 \mathrm{~mm} \mathrm{Hg}$ increase in systolic blood pressure with evacetrapib treatment in the overall study along with an $8 \%$ relative increase in highsensitivity C-reactive protein levels, both of which are unlikely to account for the observed neutrality of clinical drug effect.

The lack of efficacy despite the LDL-lowering effect seen in patients with and without diabetes on evacetrapib compared with placebo is notable. Recent studies with PCSK9 inhibitors and ezetimibe that have lowered LDL cholesterol levels in the background of statin therapy in the range similar to ACCELERATE have been associated with favorable, statistically significant relative risk reductions in cardiovascular events. ${ }^{1123}$ One possible explanation is that all of these agents with proven efficacy result in upregulation of LDL receptors while CETP inhibition acts by inhibiting the transfer of esterified cholesterol to LDL, thereby resulting in a polydispersed LDL without the same protective properties. LDL reduction by CETP inhibition also appears to overestimate the magnitude of benefit as LDL levels decrease disproportionately when compared with the absolute reduction in measured ApoB values. Countering this are findings from REVEAL trial in which anacetrapib did show a $9 \%$ reduction in cardiovascular events with CETP inhibition, largely consistent with an LDL effect in the setting of a longer duration of follow-up and with over 30000 participants. ${ }^{30}$

Our current findings have significant implications with regard to the reduction of cardiovascular risk in patients with DM. The lack of benefit noted despite sustained elevation in HDL levels suggests that modification of HDL via CETP inhibition should not be further pursued as a therapeutic target. The findings of the REVEAL study using anacetrapib also support this conclusion. CETP inhibitors thus join other lipid-lowering agents like niacin and fibrates that have failed to further reduce events in patients with DM treated with statin therapy. ${ }^{32} 33$ Alternate strategies to further reduce cardiovascular events 

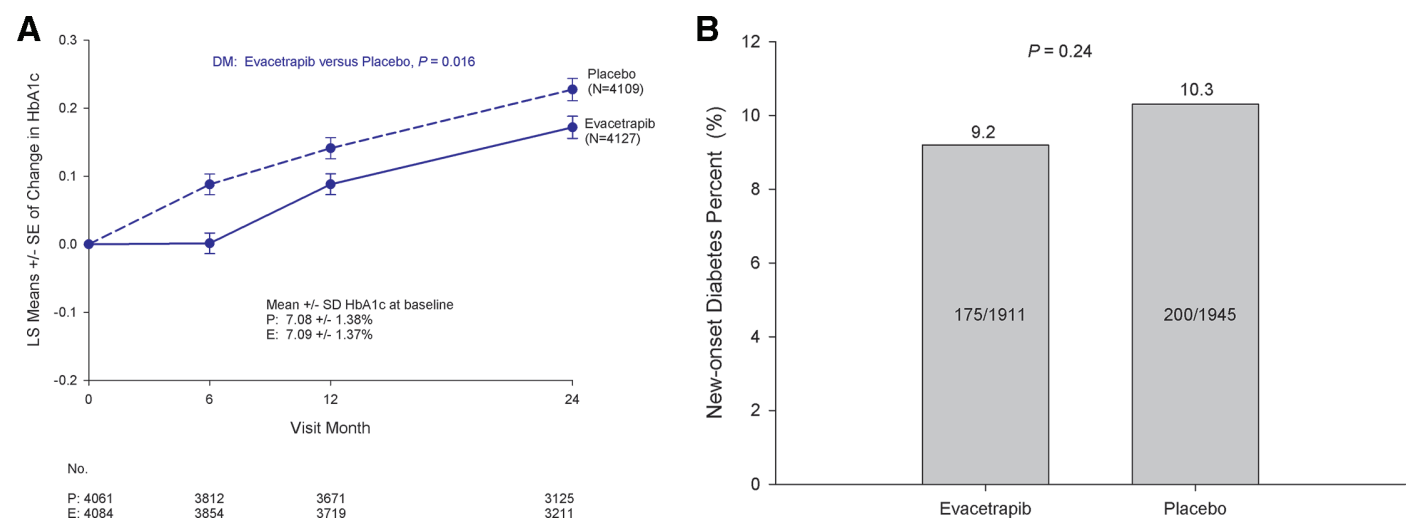

Figure 4 Impact of exposure to evacetrapib on glycemic control among patients with diabetes mellitus (A) and incidence of new-onset diabetes (B) in the Assessment of Clinical Effects of Cholesteryl Ester Transfer Protein Inhibition with Evacetrapib in Patients at a High Risk for Vascular Outcomes (ACCELERATE) trial. DM, diabetes mellitus; LS, least squares.

have now been proven or are being evaluated. Recent trials with PCSK9 inhibition confirm that intensifying LDL treatment targets from current standard of care to levels of $30 \mathrm{mg} / \mathrm{dL}$ are associated with clinical benefit without additional safety concerns. ${ }^{23} 34$ This finding is also supported by the results of the IMProved Reduction of Outcomes: Vytorin Efficacy International Trial (IMPROVE-IT) in which addition of ezetimibe to a statin to achieve a median LDL cholesterol of $50 \mathrm{mg} / \mathrm{dL}$ was associated with a clinical benefit predominantly in the population with DM. ${ }^{11}$ Another novel target to reduce cardiovascular risk in this population is to target inflammation. In patients with established coronary artery disease and remote myocardial infarction optimally treated with a statin, blockade of interleukin- $1 \beta$ with canakinumab was associated with a significant reduction in cardiovascular events independent of lipid modification. ${ }^{35}$

Exposure to evacetrapib was associated with a favorable glycemic profile in patients with and without DM. Similar findings have been previously reported with torcetrapib, dalcetrapib, and, recently, anacetrapib. ${ }^{36}$ Although the mechanism remains uncertain, these findings suggest a class effect associated with CETP inhibition. The favorable glycemic profile in ACCELERATE was associated with a numerically lower but statistically insignificant decrease in the rates of new-onset DM. This is in contrast to the REVEAL trial in which anacetrapib definitively reduced rates of new-onset DM, likely due to the larger size and prolonged duration of clinical follow-up. ${ }^{30}$ These findings with CETP inhibition are in contrast to lipid modification with statins and niacin, both of which are associated with an increase in the risk of $\mathrm{DM}^{37}$ Although genetic variants of PCSK9 inhibition have been associated with a higher risk of DM, a recent analysis with PCSK9 inhibition in the Further Cardiovascular Outcomes Research With PCSK9 Inhibition in Subjects With Elevated Risk (FOURIER) trial revealed a neutral effect with evolocumab on glycemic control. ${ }^{38} 39$

\section{CONCLUSION}

Patients with DM enrolled in the ACCELERATE trial experienced significantly greater cardiovascular events than their counterparts without DM. Treatment with

Table 3 Major adverse events in patients with diabetes mellitus

\begin{tabular}{lcccc}
\hline Adverse event & $\begin{array}{l}\text { Evacetrapib } \\
\mathbf{n} / \mathbf{N} \text { (\%) }\end{array}$ & $\begin{array}{l}\text { Placebo } \\
\text { n/N (\%) }\end{array}$ & \multicolumn{1}{l}{ Total } & P value \\
\hline Serious adverse event & $1657 / 4127(40.2)$ & $1682 / 4109(40.9)$ & $3339 / 8236(40.5)$ & 0.47 \\
\hline Hypoglycemia & $149 / 3699(4.0)$ & $138 / 3678(3.8)$ & $287 / 7377(3.9)$ & 0.54 \\
\hline Acute pancreatitis & $13 / 3699(0.4)$ & $3 / 3678(0.1)$ & $16 / 7377(0.2)$ & 0.013 \\
\hline Chronic pancreatitis & $3 / 3699(0.1)$ & $0 / 3678(0.0)$ & $3 / 7377(0.0)$ & 0.25 \\
\hline Cancer & $301 / 3699(8.1)$ & $283 / 3678(7.7)$ & $584 / 7377(7.9)$ & 0.48 \\
\hline Pancreatic cancer & $6 / 3699(0.2)$ & $11 / 3678(0.3)$ & $17 / 7377(0.2)$ & 0.22 \\
\hline Angioedema & $7 / 3699(0.2)$ & $3 / 3678(0.1)$ & $10 / 7377(0.1)$ & 0.34 \\
\hline Maximum ALT $\geq 3 \times$ ULN & $20 / 4095(0.5)$ & $21 / 4075(0.5)$ & $41 / 8170(0.5)$ & 0.86 \\
\hline Maximum AST $\geq 3 \times$ ULN & $11 / 4095(0.3)$ & $16 / 4073(0.4)$ & $27 / 8168(0.3)$ & 0.33 \\
\hline Median \% change in modified GFR (IQR) & $-1.6(-8.6$ to 5.8$)$ & $-2.4(-9.5$ to 4.5) & $-2.1(-9.0$ to 5.1$)$ & $<0.001$ \\
\hline Dialysis & $1 / 3699(0.0)$ & $1 / 3678(0.0)$ & $2 / 7377(0.0)$ & 1.000 \\
\hline
\end{tabular}

ALT, alanine aminotransferase; AST, aspartate transaminase; GFR, glomerular filtration rate; ULN, upper limits of normal. 
evacetrapib resulted in a sustained increase in HDL levels along with a decrease in LDL levels in patients with DM compared with placebo as was noted in the overall trial population. There was no observed interaction between presence of DM and treatment outcomes with evacetrapib. Similar to the results of the overall trial, no clinical benefits were noted in the large subset of patients with DM treated with evacetrapib compared with placebo.

Contributors VM and AK had full access to all the data in the study and take responsibility for the integrity of the data and the accuracy of the data analysis. VM and AK contributed to the conception and design of the study, the data analysis, the data interpretation, the manuscript drafting, and the critical revision of the manuscript. VM is the corresponding author. DRP, JStJ, JR, GW, GR, KEW, EM, PCC, SJN, AML, and SEN contributed to the design of study, the data analysis, the data interpretation, and the critical revision of the manuscript.

Funding The authors have not declared a specific grant for this research from any funding agency in the public, commercial or not-for-profit sectors.

Competing interests None declared.

Patient consent for publication Not required.

Provenance and peer review Not commissioned; externally peer reviewed.

Data availability statement All data relevant to the study are included in the article or uploaded as supplementary information.

Open access This is an open access article distributed in accordance with the Creative Commons Attribution Non Commercial (CC BY-NC 4.0) license, which permits others to distribute, remix, adapt, build upon this work non-commercially, and license their derivative works on different terms, provided the original work is properly cited, appropriate credit is given, any changes made indicated, and the use is non-commercial. See: http://creativecommons.org/licenses/by-nc/4.0/.

ORCID iDs

Venu Menon http://orcid.org/0000-0003-4410-2677

Anirudh Kumar http://orcid.org/0000-0002-4413-5439

\section{REFERENCES}

1 Rydén L, Grant PJ, Anker SD, et al. ESC guidelines on diabetes, prediabetes, and cardiovascular diseases developed in collaboration with the EASD: the task force on diabetes, pre-diabetes, and cardiovascular diseases of the European Society of cardiology (ESC) and developed in collaboration with the European association for the study of diabetes (EASD). Eur Heart J 2013;34:3035-87.

2 Rao Kondapally Seshasai S, Kaptoge S, Thompson A, et al. Diabetes mellitus, fasting glucose, and risk of cause-specific death. N Engl J Med 2011;364:829-41.

3 Assmann G, Schulte H, von Eckardstein A, et al. High-density lipoprotein cholesterol as a predictor of coronary heart disease risk. The PROCAM experience and pathophysiological implications for reverse cholesterol transport. Atherosclerosis 1996;124 Suppl:S11-20.

4 Castelli WP, Garrison RJ, Wilson PW, et al. Incidence of coronary heart disease and lipoprotein cholesterol levels. The Framingham study. JAMA 1986;256:2835-8.

5 Sharrett AR, Ballantyne CM, Coady SA, et al. Coronary heart disease prediction from lipoprotein cholesterol levels, triglycerides, lipoprotein(a), apolipoproteins A-I and B, and HDL density subfractions: The Atherosclerosis Risk in Communities (ARIC) Study. Circulation 2001;104:1108-13.

6 Barter P, Gotto AM, LaRosa JC, et al. HDL cholesterol, very low levels of LDL cholesterol, and cardiovascular events. N Engl J Med 2007;357:1301-10.

7 Thompson A, Di Angelantonio E, Sarwar N, et al. Association of cholesteryl ester transfer protein genotypes with CETP mass and activity, lipid levels, and coronary risk. JAMA 2008;299:2777-88.

8 Voight BF, Peloso GM, Orho-Melander M, et al. Plasma HDL cholesterol and risk of myocardial infarction: a Mendelian randomisation study. Lancet 2012;380:572-80.

9 Ridker PM, Paré G, Parker AN, et al. Polymorphism in the CETP gene region, $\mathrm{HDL}$ cholesterol, and risk of future myocardial infarction: genomewide analysis among 18245 initially healthy women from the women's genome health study. Circ Cardiovasc Genet 2009;2:26-33.

10 Holmes MV, Asselbergs FW, Palmer TM, et al. Mendelian randomization of blood lipids for coronary heart disease. Eur Heart $J$ 2015;36:539-50.

11 Cannon CP, Blazing MA, Giugliano RP, et al. Ezetimibe added to statin therapy after acute coronary syndromes. $N$ Engl $J$ Med 2015;372:2387-97.

12 Kearney PM, Blackwell L, Collins R, et al. Efficacy of cholesterollowering therapy in 18,686 people with diabetes in 14 randomised trials of statins: a meta-analysis. Lancet 2008;371:117-25.

13 Nicholls SJ, Brewer HB, Kastelein JJP, et al. Effects of the CETP inhibitor evacetrapib administered as monotherapy or in combination with statins on $\mathrm{HDL}$ and $\mathrm{LDL}$ cholesterol: a randomized controlled trial. JAMA 2011;306:2099-109.

14 Lincoff AM, Nicholls SJ, Riesmeyer JS, et al. Evacetrapib and cardiovascular outcomes in high-risk vascular disease. N Engl J Med 2017;376:1933-42.

15 Nicholls SJ, Lincoff AM, Barter PJ, et al. Assessment of the clinical effects of cholesteryl ester transfer protein inhibition with evacetrapib in patients at high-risk for vascular outcomes: rationale and design of the accelerate trial. Am Heart $J$ 2015;170:1061-9.

16 Scirica BM, Bhatt DL, Braunwald E, et al. Saxagliptin and cardiovascular outcomes in patients with type 2 diabetes mellitus. $N$ Engl J Med 2013;369:1317-26.

17 Green JB, Bethel MA, Armstrong PW, et al. Effect of sitagliptin on cardiovascular outcomes in type 2 diabetes. $N$ Engl $J$ Med 2015;373:232-42.

18 Zinman B, Wanner C, Lachin JM, et al. Empagliflozin, cardiovascular outcomes, and mortality in type 2 diabetes. N Engl J Med 2015;373:2117-28.

19 White WB, Cannon CP, Heller SR, et al. Alogliptin after acute coronary syndrome in patients with type 2 diabetes. N Engl J Med 2013;369:1327-35.

20 Pfeffer MA, Claggett B, Diaz R, et al. Lixisenatide in patients with type 2 diabetes and acute coronary syndrome. N Engl J Med 2015;373:2247-57.

21 Piepoli MF, Hoes AW, Agewall S, et al. 2016 European Guidelines on cardiovascular disease prevention in clinical practice: The Sixth Joint Task Force of the European Society of Cardiology and Other Societies on Cardiovascular Disease Prevention in Clinical Practice (constituted by representatives of 10 societies and by invited experts)Developed with the special contribution of the European Association for Cardiovascular Prevention \& Rehabilitation (EACPR). Eur Heart J 2016;37:2315-81.

22 Stone NJ, Robinson JG, Lichtenstein AH, et al. 2013 ACC/ AHA guideline on the treatment of blood cholesterol to reduce atherosclerotic cardiovascular risk in adults: a report of the American College of Cardiology/American heart association Task force on practice guidelines. J Am Coll Cardiol 2014;63:2889-934.

23 Sabatine MS, Giugliano RP, Keech AC, et al. Evolocumab and clinical outcomes in patients with cardiovascular disease. N Engl J Med 2017;376:1713-22.

24 Fulcher J, O'Connell R, Voysey M, et al. Efficacy and safety of LDL-lowering therapy among men and women: meta-analysis of individual data from 174,000 participants in 27 randomised trials. Lancet 2015;385:1397-405.

25 Barter PJ, Caulfield M, Eriksson M, et al. Effects of torcetrapib in patients at high risk for coronary events. $N$ Engl $J$ Med 2007;357:2109-22.

26 Schwartz GG, Olsson AG, Abt M, et al. Effects of dalcetrapib in patients with a recent acute coronary syndrome. N Engl J Med 2012;367:2089-99.

27 Nicholls SJ, Ruotolo G, Brewer HB, et al. Cholesterol efflux capacity and pre-beta-1 HDL concentrations are increased in dyslipidemic patients treated with Evacetrapib. J Am Coll Cardiol 2015;66:2201-10.

28 Khera AV, Cuchel M, de la Llera-Moya M, et al. Cholesterol efflux capacity, high-density lipoprotein function, and atherosclerosis. $N$ Engl J Med 2011;364:127-35.

29 Rohatgi A, Khera A, Berry JD, et al. HDL cholesterol efflux capacity and incident cardiovascular events. N Engl J Med 2014;371:2383-93.

30 Bowman L, Hopewell JC, Chen F, et al. Effects of anacetrapib in patients with atherosclerotic vascular disease. N Engl J Med 2017;377:1217-27.

31 Marso SP, Bain SC, Consoli A, et al. Semaglutide and cardiovascular outcomes in patients with type 2 diabetes. N Engl $\mathrm{J}$ Med 2016;375:1834-44. 
32 Boden WE, Probstfield JL, Anderson T, et al. Niacin in patients with low HDL cholesterol levels receiving intensive statin therapy. $N$ Engl J Med 2011;365:2255-67.

33 Landray MJ, Haynes R, Hopewell JC, et al. Effects of extendedrelease niacin with laropiprant in high-risk patients. $N$ Engl J Med 2014;371:203-12.

34 Giugliano RP, Pedersen TR, Park J-G, et al. Clinical efficacy and safety of achieving very low LDL-cholesterol concentrations with the PCSK9 inhibitor evolocumab: a prespecified secondary analysis of the Fourier trial. Lancet 2017;390:1962-71.

35 Ridker PM, Everett BM, Thuren T, et al. Antiinflammatory therapy with canakinumab for atherosclerotic disease. N Engl J Med 2017;377:1119-31.

36 Barter PJ, Rye K-A, Tardif J-C, et al. Effect of Torcetrapib on Glucose, Insulin, and Hemoglobin $A_{1 c}$ in Subjects in the
Investigation of Lipid Level Management to Understand its Impact in Atherosclerotic Events (ILLUMINATE) Trial. Circulation 2011;124:555-62.

37 Goldie C, Taylor AJ, Nguyen P, et al. Niacin therapy and the risk of new-onset diabetes: a meta-analysis of randomised controlled trials. Heart 2016;102:198-203.

38 Lotta LA, Sharp SJ, Burgess S, et al. Association between lowdensity lipoprotein cholesterol-lowering genetic variants and risk of type 2 diabetes: a meta-analysis. JAMA 2016;316:1383-91.

39 Sabatine MS, Leiter LA, Wiviott SD, et al. Cardiovascular safety and efficacy of the PCSK9 inhibitor evolocumab in patients with and without diabetes and the effect of evolocumab on glycaemia and risk of new-onset diabetes: a prespecified analysis of the Fourier randomised controlled trial. Lancet Diabetes Endocrinol 2017; 5:941-50. 